\title{
“A RHYTHMIC JOURNEY THROUGH TIME AND SPACE”- A STUDY OF ANCIENT SOUTH INDIAN DANCE AND TEMPLE ARCHITECTURE
}

\author{
K. Chithralekha \\ MES College of Architecture, University of Calicut, Kerala, India \\ Email: lekha.jesan@gmail.com
}

\begin{abstract}
The two physical models, dancer and architecture coexist as an intertwined system of Hindu philosophy. Both dance and dancer function as a vehicle for divine invocation and are mirrored in the architectural surroundings. This paper attempts to illustrate the deeply seated connection between ancient south Indian dance and architecture so that we can see the symbiotic relationship of both of these arts and their mutual dependence in aesthetic expression. The Hindu philosophy of the cosmic man and its religious relationship with the Dravidian architecture of Tamil Nadu is the starting point of the discussion of south Indian aesthetics. The temple, as a setting for dance performances, and constructed based on the mandala, shares this quality of immersing its participants into a multi-sensory spatial experience.
\end{abstract}

Keywords: South Indian Dance; Temple Architecture; Natyashastra; Aesthetics

\section{Introduction}

In India, dance has been an integral part of every performing art and the very essence of cultural performances. The panorama of Indian classical dances provides an answer to the unique, yet diverse cultural heritages of the different regions. It seems to uphold the truth behind the statement of 'unity in diversity' and the saying from the Upanishad i.e. 'the ultimate Truth is one but the paths leading to it are many.'

According to Kapila Vatsyayan, "Classical Indian architecture, sculpture, painting, literature, music and dancing evolved their own rules conditioned by their respective media, but they shared with one another not only the underlying spiritual beliefs of the Indian religious and philosophic mind, but also the procedures by which the relationships of the symbol and the spiritual states were worked out in detail" (Vatsyayan, 1974).

\section{Aim}

The intention of this study is to rediscover and understand the technical, artistic and spiritual complexity of ancient south Indian temple architecture and dance.

\section{Objectives}

- To examine the evolution of Bharathanatyam, a south Indian dance form, in parallel with south Indian architectural identity.

- To illustrate the links between its structure, symbolism and performance space in an intricately woven cultural fabric. 


\section{Methodology}

- Preliminary understanding of Indian classical dance forms and its evolution through literature reviews.

- Analysing the fundamentals and theoretical frameworks for south Indian dance and temple architecture.

- Exploring the elements which contribute to its mutual dependance by analysing the case study.

\section{Indian Classical Dance}

Sangeet Natak Akademi (also called as the National Academy for Music, Dance and Drama) set up by the Ministry of Culture, Government of India, has recognized India has eight classical dance forms. They come under a single umbrella term: Indian Classical Dance. These eight forms originate from different states and communities of the nation and are named as follows (Ministry of Culture, 2016).

1. Kathak from Uttar Pradesh and Rajasthan

2. Manipuri from Manipur

3. Odissi from Orissa

4. Kuchipudi from Andhra Pradesh

5. Bharathanatyam from Tamil Nadu

6. Kathakali from Kerala

7. Mohiniyattam from the borders of Tamil Nadu and Kerala, and

8. Sattriya from Assam

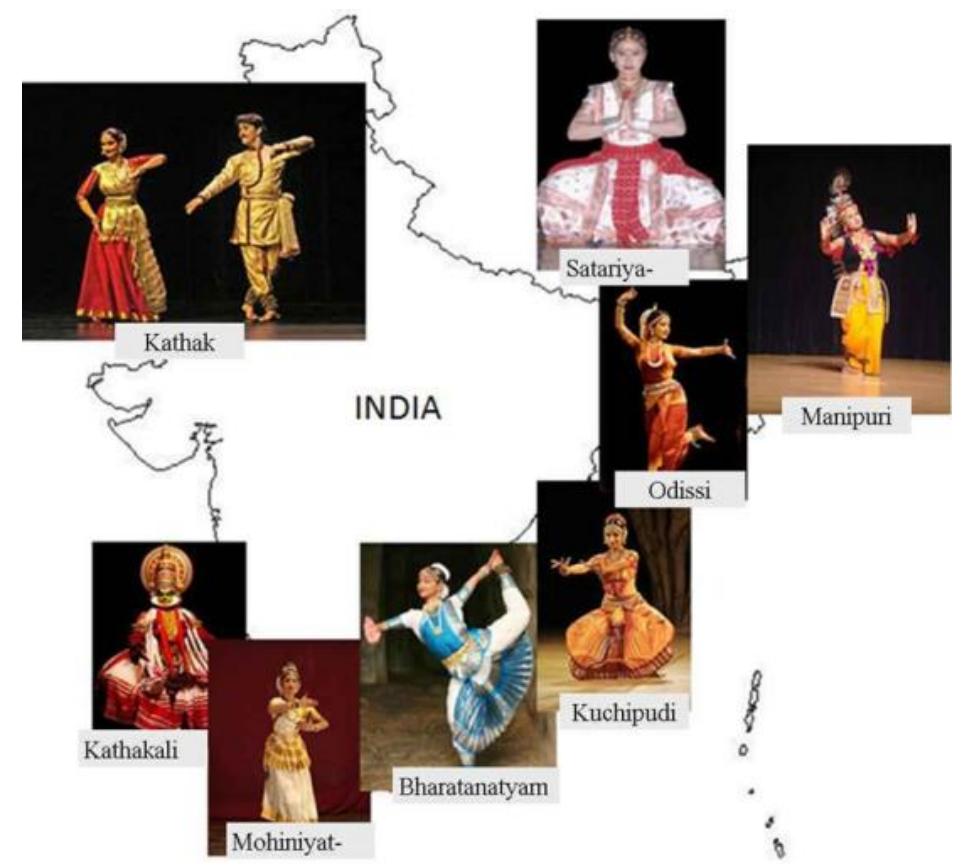

Figure 1 Eight Classical dance forms recognized in India

Each of these dances has a uniqueness of its own. Each is vividly distinguishable from the rest all in terms of its traditional repertoire of dance movements, dancing style, conventional structure of performance, traditionally choreographed dance items, musical accompaniment, and so on. And yet all the eight have strong commonalities among each other (Sukhatankar, 2016). That is, they all are thoroughly 'Indian' and 'classical' in their artistic spirit, their nature and culture, and their roots are founded in ancient Indian theory of performing arts. 


\section{Evolution of Indian Performing Arts}

India is a land of rich culture and heritage. Since the beginning of our civilization, music, dance and drama have been an integral aspect of our culture. Initially, these art forms were used as medium of propagation for religion and social reforms in which music and dance were incorporated to gain popularity. From the Vedic era to the medieval period, the performing arts remained as an important source of educating the masses (Vatsyayan, 1971).

It is of great interest to note that the origin of dance in our country is traced to divine causes. The sacred art of dance is said to have been the brain-child of Brahma, the creator in the Hindu Trinity of gods. The term 'dance' is used in our country for want of a more appropriate equivalent of the Sanskrit 'Natya' which embodies a combination of dance, drama and music. In Indian art these three are closely related and can never be completely diverged from each other.

The dramatic scriptures of our country are said to have been brought into human being by Brahma at the request of the lesser gods. The blessed Brahma framed the Natya Veda gathering parts from the four Vedas. From the Rig Veda he drew forth words, from Sama Veda, singing, from Yajur Veda, gesture and from Atharva Veda, flavour. Brahma taught this science of 'Natya' to Bharata Muni and his hundred sons and Bharata compiled the rules and norms of this artistic science or scientific art into his famous treatise 'Natyashastra' (Bose, 1989). All classical dances in India can be traced back to this 'Natyashastra'. Due to varying local and social factors that always influence art, dance in different regions took on various hues.

To investigate this connection between dance and place, it is imperative to understand the mythical origins of architecture and temple dance. In dealing with the subject, I limit myself to Bharathanatyam, the South Indian classical dance, although the same rules should apply to dances all over the world. We, in India are very fortunate still to be in the possession of dances from very primitive types to the most stylized and advanced classical forms. Given that the early as well as the later works on dancing move within the framework of description set up by Bharata, it is essential to examine that framework closely.

\section{Bharathanatyam}

Bharathanatyam was originated in Southern India in the state of Tamilnadu. The name Bharathanatyam is a simple derivation from four most important aspects of dance.

- BHA- from "Bhava" meaning Emotion

- RA- from "Raga” meaning Music or Melody

- $\quad$ THA- from "Thala” meaning Rhythm

- Natyam meaning Dance 


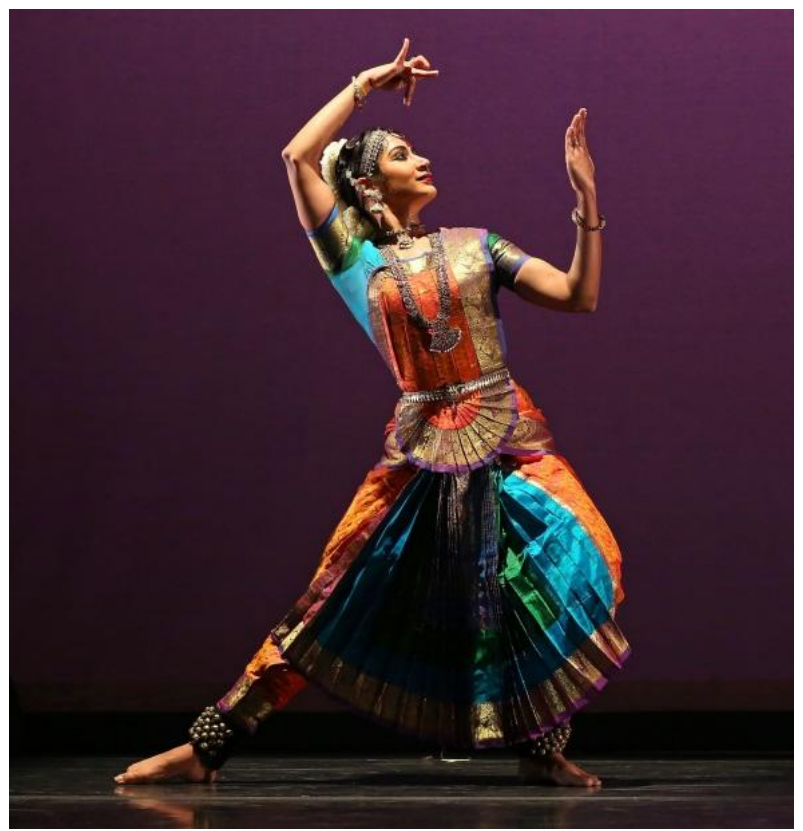

Figure 2 Bharathanatyam, a Southern Indian Classical Dance form

It started as a temple dance tradition called Dasiyattam done by Devadasis. The word Devadasi literally means the "Servants of God". They were the special group of people who used to live in the temples totally dedicated to the service of God. These Devadasis were maintained by the Kings and all their needs were looked after. They enjoyed a very high social status because they were very well versed in dance, music in other arts and literature. They enjoyed a great deal of respect in the society. This continued for a very long time, especially under the rule of Pallava and Chola Kings which was a great period for construction of temples in India. So the art of dance really flourished in the temples and it was used as a part of day to day worship of God (Bose, 1970).

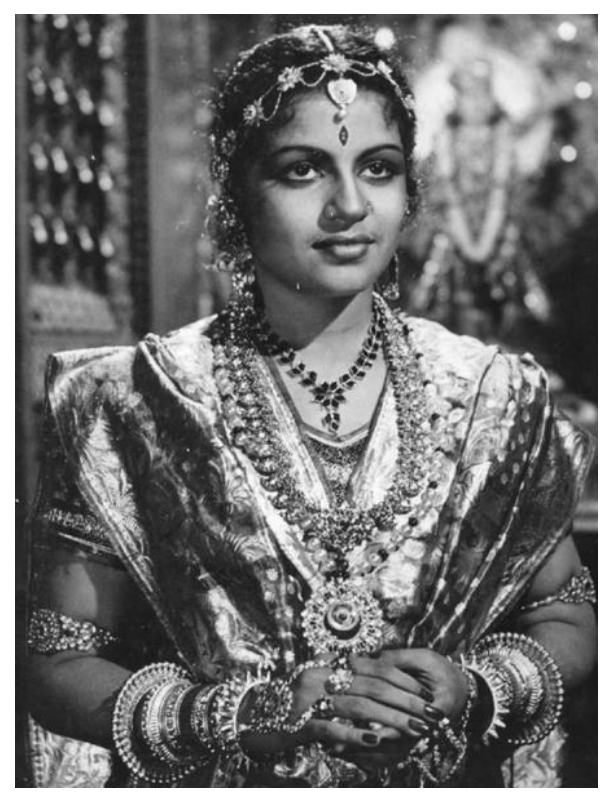

Figure 3 A Devadasi who was dedicated to the service of God

\section{Temple and Society}

In Hindu culture, temple is not only a place of worship but they act as a centre for intellectual and artistic life. The temple complex housed schools, hospitals and courts for the community. The spacious halls of the temple 
were the place for the recitation and listening of folk tales, Vedas, Ramayana, Mahabharata and debates. Music and dance were the part of daily rituals in the temple (Lopez y Royo, 2010). The presence of these activities eventually gave the people more knowledge about the traditions and made them appreciate the older practices. Temple provided means of livelihood for a large number of persons and greatly influenced the economic life of the community. The temple is the centre of all aspects of the life of the community and every member of the community contributed in the up keeping and building of temple. Although the temple is the hub of different religious and cultural activities, the nucleus is the main shrine.

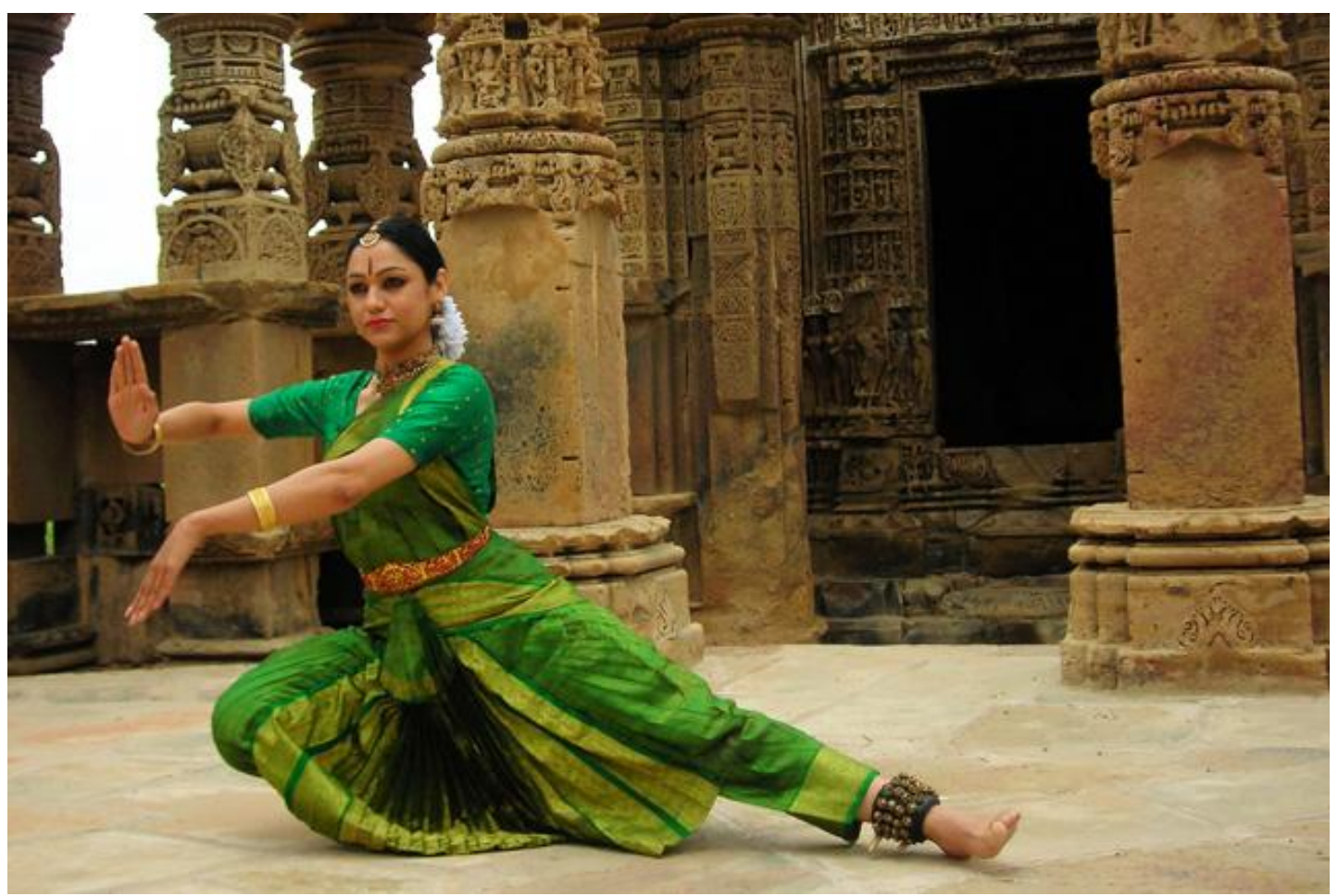

Figure 4 Hindu Temple acts as a centre for intellectual and artistic life

\section{Foundation of South Indian Temple Architecture}

The typical plan of a Hindu temple is an illustration of sacred geometry where the temple is a representation of the mandala. Here the sacred geometry means the science of the accurate laying out the ground floor of the temple in relation to the astronomical movements and positions and the cardinal directions. The visual representation of the Vastupurusha as a governing device for making a building is called a Vastupurusha mandala. The form of the mandala is derived from a square contained within a circle. The circle represents the movement and cyclical time of the terrestrial world. The perfect square, representing the non-moving absolute form is attributed to the celestial world and is inscribed within the circle. 


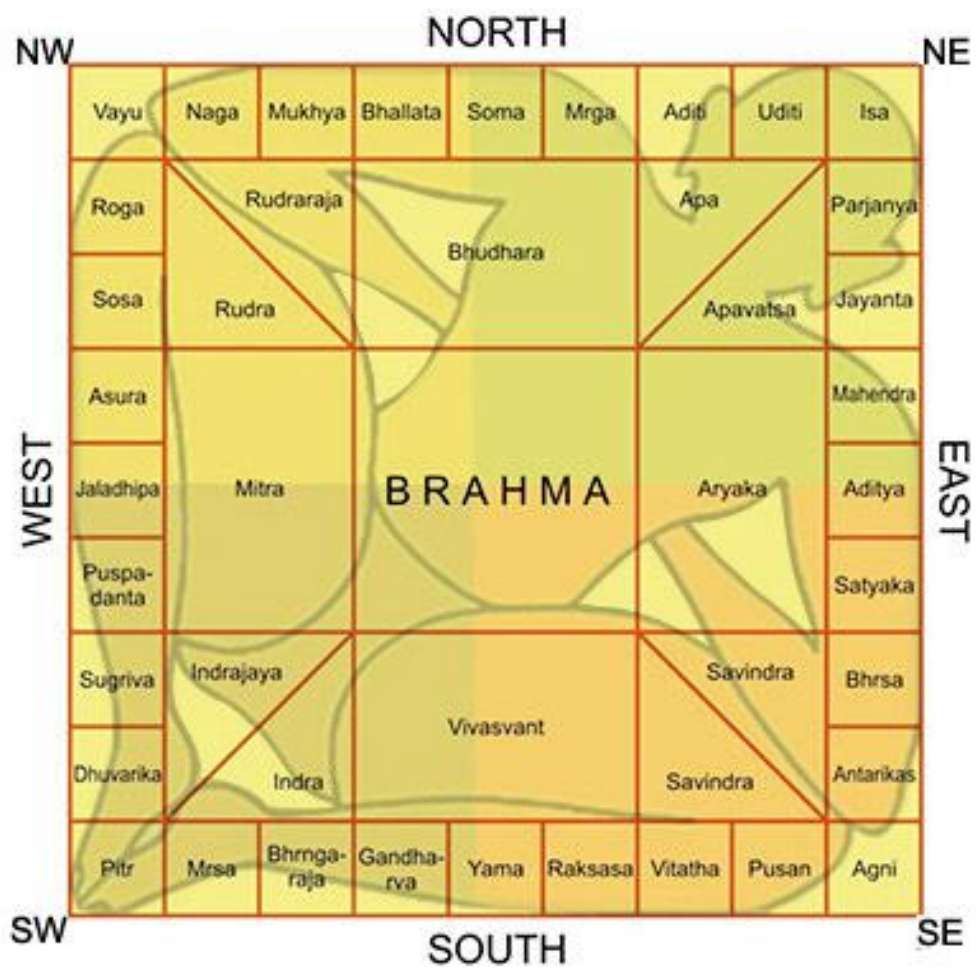

Figure 5 Vastupurusha mandala

Drawn within this geometry, Maha Purusha takes a yogic pose relating to his mortal likeness - man. With his spine acting as the vertical axis he divides earth and sky, binding the cyclical world of the cosmos to the physical world of man, allowing worshippers to comprehend man and the heavens simultaneously. The size, divisions and technical details of the Vastupurusha mandala are set out in the Vedic text, Vastushastra. Falling under a branch of the occult, this text on the science of building was passed down through an oral tradition from father to son, maintaining the integrity and secrecy behind this divine science (Hardy, 2007).

The mandala is divided primarily into a nine square grid, beyond which there is a variety of geometric derivations that can be drawn upon depending on the structure. The Sthapati (architect) is required to follow the guidelines set out in the texts in order to symbolically maintain both terrestrial and cosmic laws as it is in the very mathematical divisions that Purusha is contained. The Vastupurusha mandala is thus a reflection of all existence, and is fundamental in the realization of cosmic design, whether manifested in the body, house, temple, city or universe. 


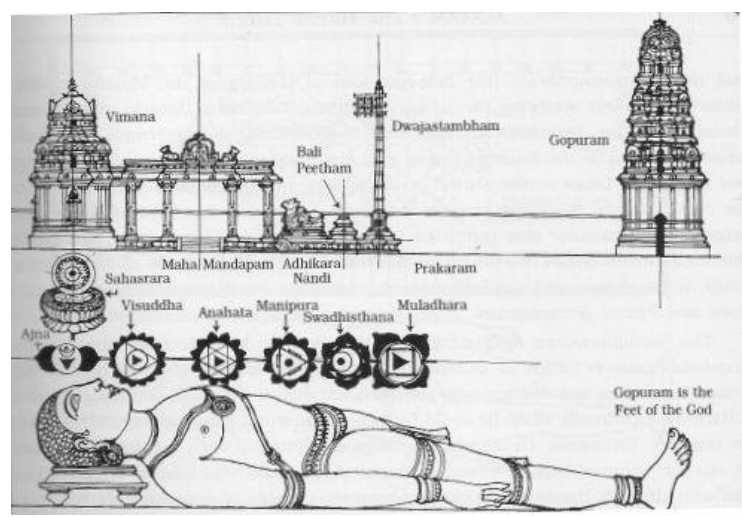

Figure 6 Temple as the body of deity

The temple was seen not only God's dwelling but was also a physical manifestation of the divinity it housed, comparable to sacred counterparts in the natural world. Through the siting of the temple and the execution of its plans and elevations, the form of the temple was linked back with those of the universe, where mountains, rivers and caves aligned the built complex to its cosmic axis (Vardia, 2008). Derived from the mandala, the temple represented the mythical Mount Meru; surrounded by continents, oceans and supporting heavenly bodies, it is considered by Hindus to be the 'navel' of the universe. The adorned gopura or mountain-like superstructure of a temple ends in a vimana or mountain peak, with the horizontal tiers of the roof with temple structure reminiscent of bhoomi or earthly strata. The dimly lit, unadorned massive walled sanctuary represented an architectural expression of a cave.

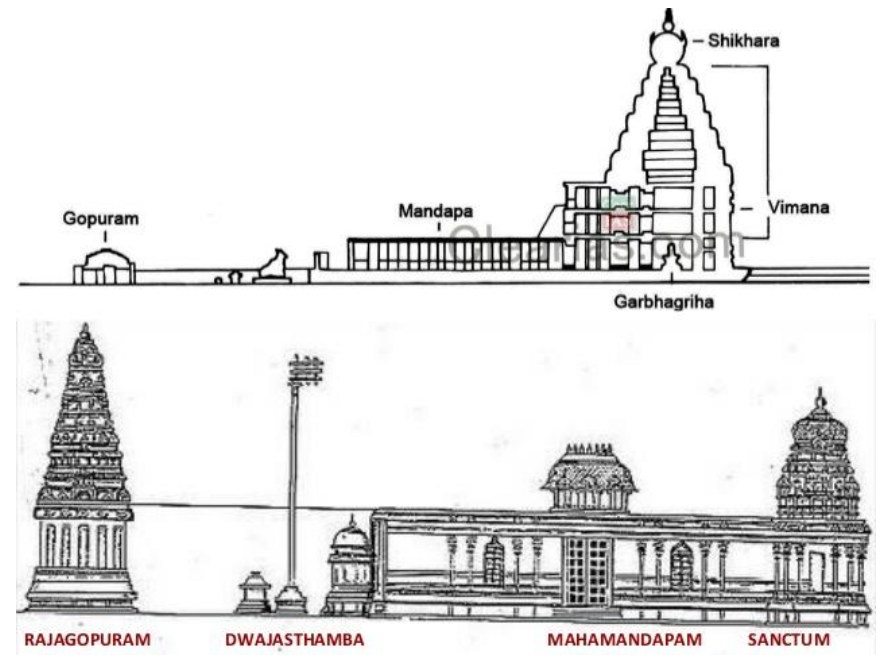

Figure 7 Typical features of a South Indian Temple

\section{Foundation of South Indian Classical Dance}

Dance has a very important role in India as part of worship. Natyashastra is the most elaborate of all the treatises on acting and dramatic criticism ever written in any language. It covers stage design, music, dance and make up eventually every aspect of the stage craft. Sage Bharata is said to have written this great work Natyashastra. It has 37 chapters and it is about 2000 years old. The first half of Natyashastra deals with Rasa and the second with prose. The latter includes the chapter on architecture, the most ambiguous of all the chapters.

The content of the performances differed from those of other ancient cultures. While European tragedies evoked a questioning attitude of a search for meaning in life's burdens, the Natyashastra describes theatre as a celebration of life and a testament to the joy of divine worship (Harp Allen, 2010). 
Analysis of the framework of South Indian Dance is done in regard with three dimensions or aspects which are the building blocks for the performing art (Nritya). They are;

1. Technical Aspect (Nritta)

2. Expressional Aspect (Natya)

3. Musical Aspect (Geetam and Vadyam) (Coomaraswamy and Duggirala, 1917)

\section{Technical Aspect (Nritta Theory)}

Nritta is the technical aspect of dance that looks at dancer's bodily gestures without looking at its dramatic aspect. It also does not focus on the musical aspect of bodily gestures such as tempo, rhythm etc. It rather focuses on, mainly, two things:

- The actual gestures or movements that are danced

- The dancer's body which executes those movements.

Shilpa Shastra (Science of Arts and Crafts) mentions four basic postures of the idols in temples. They are the Sthanaka (standing), Aasana (seated), Shayana (reclining) and Yanaka (relating to deities like Hanuman or Garuda who serve as the ride for other deities). Each of these postures has its sub classifications (Hardy, 2007).

The Sthanaka posture (standing posture) of the image will be in accordance with its nature and its attitude of benevolence or otherwise. That expression of benevolence, grace or the other attitude depicted on the face of the image is enhanced by the manner and style of its stance. The standing postures are named Bhanga, which involves appropriate stance, position and bent of the neck (greeva), shoulder (bhuja), waist (kati), knees (janu) and feet (paada).

The basic styles of the standing postures are five in number. Samabhanga is standing erect, with the head, neck and torsos in a line, radiating peace, fulfilment and benediction. Natyashastra mentioned the same postures for the dancers. Hence the architecture of the human body created by these postures is quite elegant.

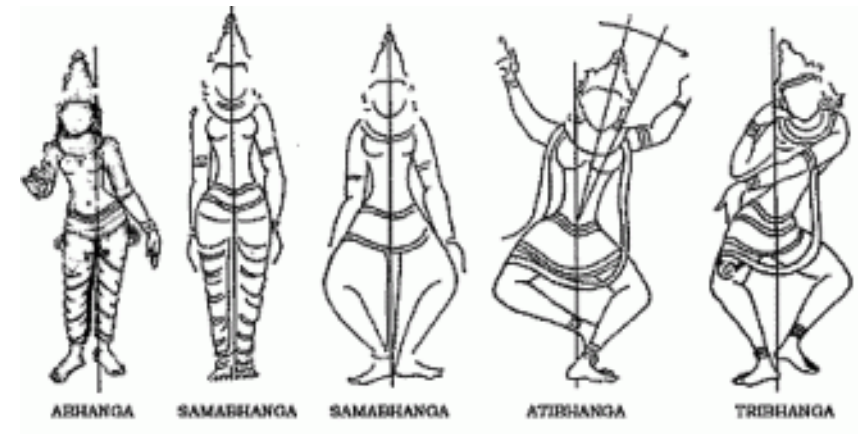

Figure 8 The basic styles of the standing postures (Sthanaka)

The dancer traverses the space along lines or in triangular formations, creating a symmetrical pattern where one half of the body is usually static. It produces a kind of aesthetics because of the geometry of physical form as it moves in space. Each step is grounded and reinforced in the sound of her anklets as her feet dances through various rhythmic iterations only to return to the balanced Samabhanga pose. As such, she does not make use of 'gliding' footwork and is seldom completely off the ground, common to other dance styles such as ballet. This dance style is characterized by linear form of the body and linear spatial patterns which make the dance form extremely dynamic and powerful.

\section{Expressional Aspect (Natya Theory)}


Whereas Nritta includes the study of human body and gestures, Natya includes the study of human emotions and personalities (Namboodiripad, 2012).

\section{Musical Aspect (Geetam and Vadyam Theory)}

The Natyashastra gives a broad theory about both vocal music (geetam) and instrumental music (vadyam).

\section{Play house or Theatre described by Natyashastra}

Natyashastra describes various types of playhouses and their different parts have been mentioned to some extent in detail (Ghosh, 1950). One remarkable feature of the playhouses described in the Natyashastra is that they are of a very moderate size. This is in sharp contrast with the Athenian theatre which sometimes held as many as fifteen thousand people.

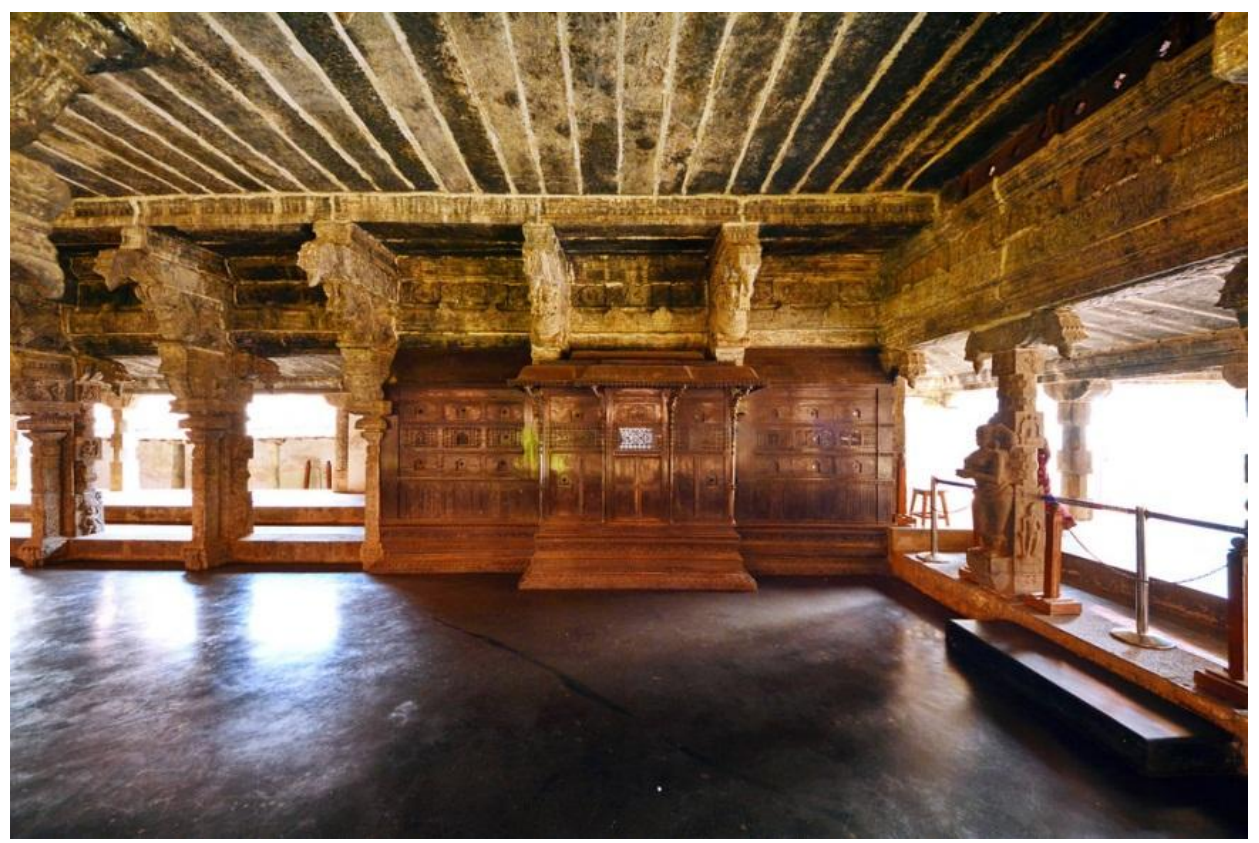

Figure 9 Playhouse attached to the Temple

The Natyashastra describes three main types of playhouses: Oblong (Vikrsta), Square (Caturasra) and Triangular (Tryasra). These again might be the large, medium or small with their length respectively as one hundred and eight, sixty four and thirty two cubits. This gives altogether nine different varieties of theatres, viz. (1) the large oblong, (2) the large square, (3) the large triangular (4) the medium oblong (5) the medium square (6) the medium triangular (7) the small oblong (8) the small square (9) the small triangular. These nine types can also be measured in terms of dandas instead of that of cubits. This will give us eighteen different dimensions of playhouses. The large playhouse is meant for Gods and the medium one for Kings while for the rest of the people has been prescribed the smallest (theatre). According to Natyashastra this play house should be divided into three parts. (1) the tiring room (Nepathya) (2) the stage (Rangapitha or Rangasirsa) and (3) the auditorium (Rangamandala)

\section{Nataraja Temple at Chidambaram, Tamilnadu}

Located in Tamilnadu, Chidambaram is home to the famous Nataraja Temple. The temple houses one of India's most iconic sculptures and represents the seat of one of Hinduism's sacred philosophies, finding bliss within the heart of man. The physical edifice of this temple and the mythology surrounding the sculptural iconography link the human body, architecture and dance. Together, they present cycles of life, death and the creation of the universe (Jayakrishnan, 2011). 


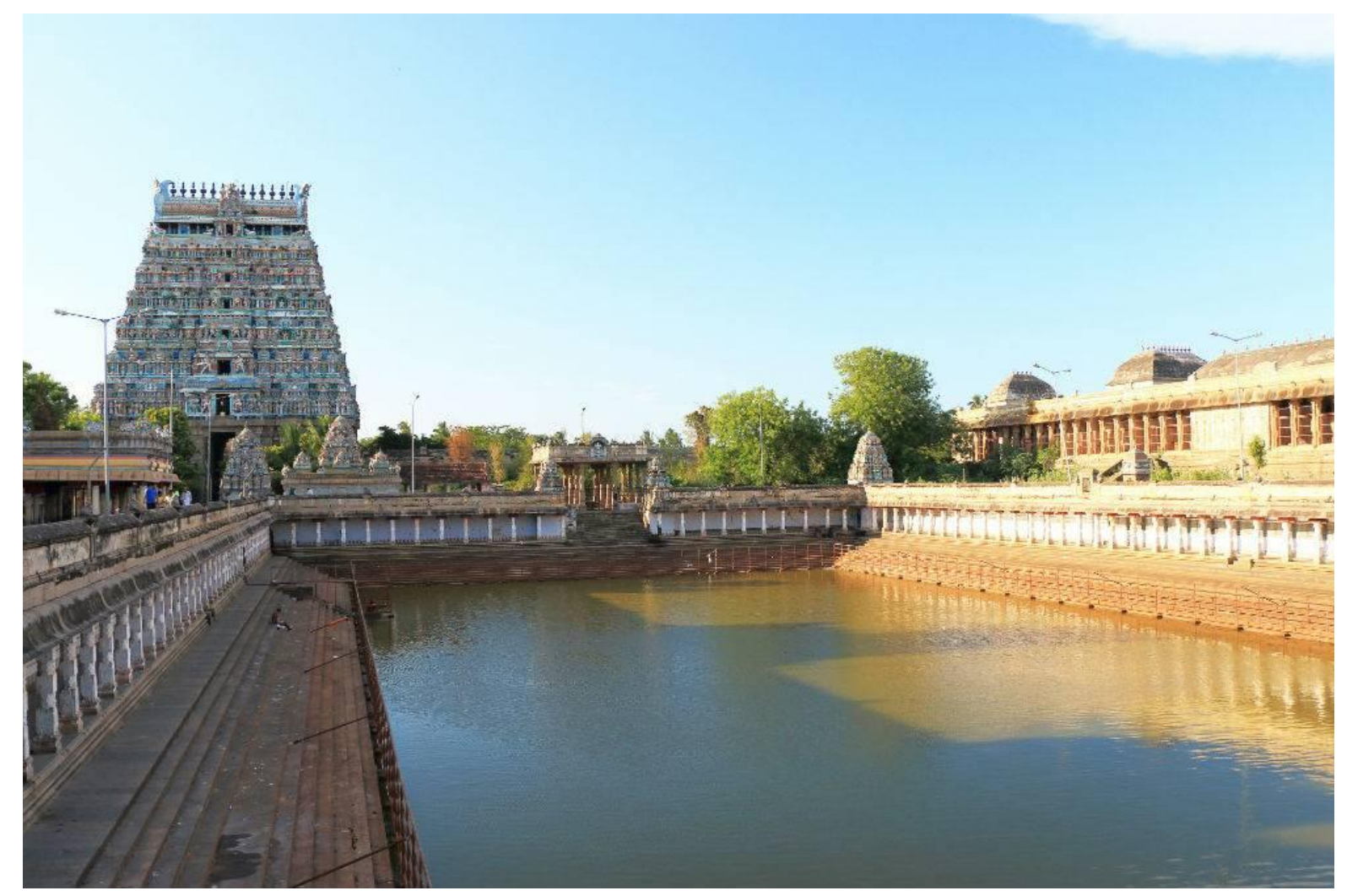

Figure 10 Nataraja Temple at Chidambaram, Tamilnadu

Built by the Cholas between $12^{\text {th }}$ and $13^{\text {th }}$ century the massive temple complex is built in the Dravidian style. The Nataraja Temple at Chidambaram, mentioned in the ancient Hindu scriptures is quite unique as it is dedicated to Lord Shiva the cosmic dancer. He is worshipped here in his dancing form (Nataraja) rather than the usual Shiva Lingam. Lord Shiva is seen here performing the Ananda Tandava (the cosmic dance of bliss), an image the world has come to recognize. The cosmic dance represents the five divine acts: creation, sustenance, destruction, concealment (Maya) and blessing.

Lord Shiva is worshipped in different forms (earth, water, fire, wind and space) in different temples. The element here is space. The temple itself is dedicated to the dance form, Bharathanatyam. 


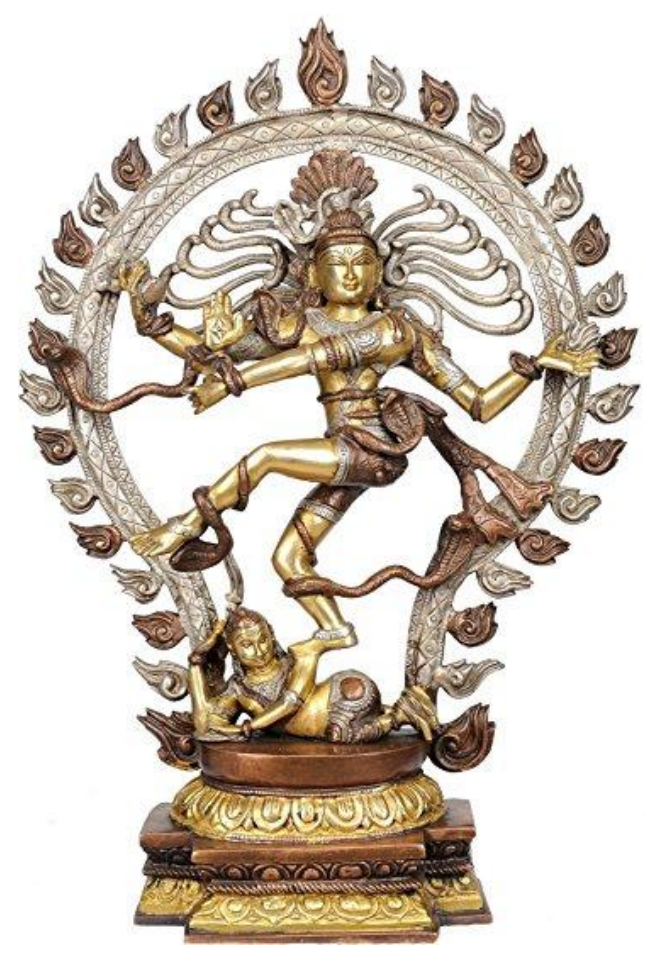

Figure 11 Lord Shiva performing the Ananda Tandava (Cosmic Dance of Bliss)

The temple has nine gateways and four of these have towering pagodas or Gopurams each with seven levels in the East, South, West and North. The eastern Gopuram has all the postures (karnams) of Bharathanatyam sculpted on it. Not only is this temple famous for its admiring architecture and devotional activities, this is the only temple where 108 Bharathanatyam dance poses are shown as depicted in Natyashastra. Each sculpture showcases the different aspects of human life. These dance poses on the walls of this temple were brought to life by Devadasis or the Servants of God as mentioned earlier.

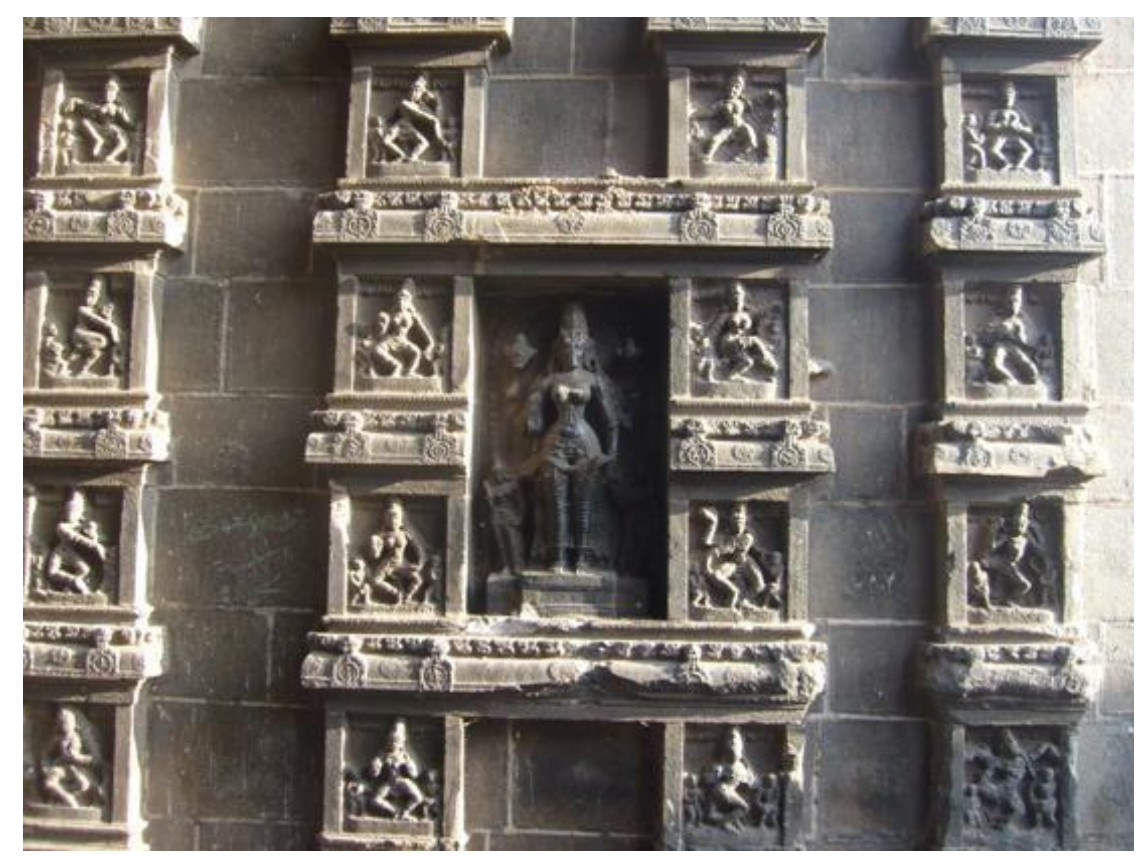

Figure 12 Poses (karnams) of Bharathanatyam sculpted on the wall

Far from a static edifice, the building itself is constantly participating in the movement, the culmination of which is visualized in the iconic Nataraja, representing a multisensory transformation. This 'final' manifestation 
of dynamism cycles back to the fundamental movement of energy, both spiritually and physically. Just as networks and bodily organs are necessary for a healthy physiology, so too are the interdependent components of south Indian culture needed for a strong community backbone.

\section{Conclusion}

The dance of bliss is not only a mythological description of progression through spiritual enlightenment but reflects the fundamental physics underlying all creation. Architectural cues, ornamental sculpture and the design criteria of the shrines, reiterate this rhythmic momentum. Hence the body participates in a basic progression of spirituality as worshippers enter the temple grounds and proceed to the inner sanctum.

The development of the Natyashastra as a codifying document speaks to the living and evolving nature of both dance and building elements forming a comprehensive whole, based on the principles of the mandala rather than a pre-envisioned generator of design. The temple, as a setting for dance performances, and constructed based on the mandala, shares this quality of immersing its participants into a multi-sensory spatial experience. Similar to the relationship of temple and dancer, contemporary artistic institutions need to recognize and cultivate design models that reflect a meaningful unification and blending of architectural, cultural and moral languages.

\section{References}

Alessandra Lopez y Royo, 2010, Indian Classical Dance: A Sacred Art, The Journal of Hindu Studies, Advance Access Publication, 2010; 3:114-123

Bose, M, 1970. Classical Indian Dancing: A Glossary, Calcutta: General Printers and Publishers.

Bose, M, 1989, “The Evolution of Classical Indian Dance Literature: A Study of the Sanskritic Tradition", Ph.D. thesis, Oxford University

Coomaraswamy A, Duggirala G K, 1917, The Mirror Of Gesture: Being The Abhinaya Darpana Of Nandikesvara, Oxford University Press, London

Hardy, A., 2007. 'The dance performed by the temple- The dynamics of Hindu temple architecture'. Paper presented at the Shivdasani Conference, Oxford Centre for Hindu Studies, Trinity College, Oxford

Harp Allen, Matthew, 2010, Rewriting the Script for South Indian Dance from Bharatanatyam: a reader, New Delhi, Oxford University Press, 205-252

Kapila Malik Vatsyayan, 1971, Aesthetic theories underlying Asian performing arts, The Performing Arts in Asia, Unesco Paris, 15-27

Kapila Malik Vatsyayan, 1974, Indian Classical Dance, New Delhi: Publications Division

Kavitha Jayakrishnan, 2011, “Dancing Architecture”, University of Waterloo, Canada

Manomohan Ghosh, 1950, "The Natyashastra”, The Royal Asiatic Society of Bengal, Calcutta

Ministry of Culture, 2016, Government of India, Dance, http://www.indiaculture.nic.in/dance

Narayanan Chittoor Namboodiripad, 2012, Revealing the Art of Natyashastra, Munshiram Manoharlal publishers Pvt. Ltd, New Delhi

Ojasi Sukhatankar, 2016, Indian Classical Dance Forms (ICDs): Three Dimensions of Analyzing Their Unity and Diversity, Chitrolekha International Magazine on Art and Design, Vol. 6(1)

Vardia, Shweta, 2008, "Building Science of Indian Temple Architecture”, University of Minho, Minho, PT

\section{Appendix}

Figure 1 Eight Classical dance forms recognized in India

Figure 2 Bharathanatyam, a Southern Indian Classical Dance form

Figure 3 A Devadasi who was dedicated to the service of God

Figure 4 Hindu Temple acts as a centre for intellectual and artistic life 
Figure 5 Vastupurusha mandala

Figure 6 Temple as the body of deity

Figure 7 Typical features of a South Indian Temple

Figure 8 The basic styles of the standing postures (Sthanaka)

Figure 9 Playhouse attached to the Temple

Figure 10 Nataraja Temple at Chidambaram, Tamilnadu

Figure 11 Lord Shiva performing the Ananda Tandava (Cosmic Dance of Bliss)

Figure 12 Poses (karnams) of Bharathanatyam sculpted on the wall 